\title{
Analysis of Proportional Integral Derivative Controller Parameters for CSTR
}

\author{
T. SUDHA \\ Department of Instrumentation and Control Engineering, \\ Sri ManakulaVinayagar Engineering College, Puducherry, INDIA.
}

\begin{abstract}
Continuous Stirred Tank Reactor (CSTR) plays a vital role and presents a various scope of researchers in the field of control and chemical engineering which exhibits of highly nonlinear behaviour and has wide operating ranges. Different control methods have been implemented on CSTR to control these parameters. Tragically, in the realcase, the behaviour of the CSTR is very different from that expected ideal CSTR which leads to the outcomes of the wrong product. However, it is a challenging task for every engineer to control the CSTR.PID controller has been proposed for adjust enhanced PID parameters in a CSTR operation utilizing a weighted mix of target capacities. Streamlining of PID controller parameters is the key objective of concoction and biochemical businesses. PID controllers have restricted the working scope of procedures with effective nonlinearity. This work considers some issues in CSTR and presents the efforts of existing researchers and it comes into view as an essential new method to adjust the control parameters. This work plans to investigate the various techniques in CSTR along with its solutions and these schemes have been surveyed in this work. This survey presents the comparison of various methods for optimizing parameters in CSTR are employed and compared with certain parameters.
\end{abstract}

Key-words: Continuous Stirred Tank Reactor (CSTR), Proportional Integral Derivative (PID), NonLinear Characteristics, Integral Square Error and Nonlinear Ordinary Differential equations.

Received: January 14, 2021. Revised: July 2, 2021. Accepted: July 18, 2021. Published: July 27 , 2021.

\section{Introduction}

Nowadays, various controlling techniques are utilized for linear and nonlinear systems especially for process control industries. Chemical reactors regularly have noteworthy warmth impacts, therefore this critical to have the capacity to include or eliminate warmth impacts from them.

Mostly conventional controllers are generally utilized due to their simple structure and its tuning strategy despite the fact it is simple but it fails to perform well for non-linear processes. CSTR is a complicated nonlinear framework due to this conduct it is generally utilized for the issue of restraint and verification of CSTR remains the critical section for control frameworks. Proposed research focused on Continuous stirred tank reactors due to strong nonlinear behaviour.

CSTR are MIMO and extremely nonlinear which have been broadly utilized helped as a benchmark for investigatingvarious control systems. The chemical industry is a critical mainstay of the national economy. The CSTR is a chemical reactor which is complex due to heat effect of span delay effect, effect of different span-varying uncertainties, the chemical reactions, and nonlinear characteristics, which is utilized as a key component of equipment required to complete chemical reactions process. CSTR are open systems, where the substantial is grant to enter or exit the process that performs on a steadystate basis, where the limits in the reactor don't shift with span. Reactants are frequently initiate into the reactor, while amounts are constantly expelled.

CSTR is common processing unit in polymer and chemical industry which typically operates on consistent state, and in which stimulant are included and amounts are eliminated persistently at a static amount while the reaction blend quite well stirred using internal factors, so the contents have generally uniform properties such as temperature, density, etc. throughout.

It is designed with zero dimensional adjustment in temperature, absorption or reply 
amount all through the vessel. Since the concentration and temperature are constant within the reply vessel and also constant at the exits point. CSTR is defined by three basic parameters such as flow rate, retention time and dilution rate.

\section{CSTR Requirements in Applications}

- Good temperature control is effectively kept up in the reactor.

- Cheap to build, particularly at high throughputs.

- The reactor has a huge warmth limit and Interior of the reactor is effectively available.

- Consistent product quality due to reproducible process control.

CSTR mainly preferred for real-time applications in chemical and wastewater treatment industries due to its suitable mixing property and it plays a vital role in chemical, petrochemical and pharmaceutical industries. Mainly it often utilized in synthetic business and particularly exothermic CSTRs are exceptionally intriguing frameworks from the limited perspective as a result of the possible security issues and the probability of exotic behavior even in various reliable case.

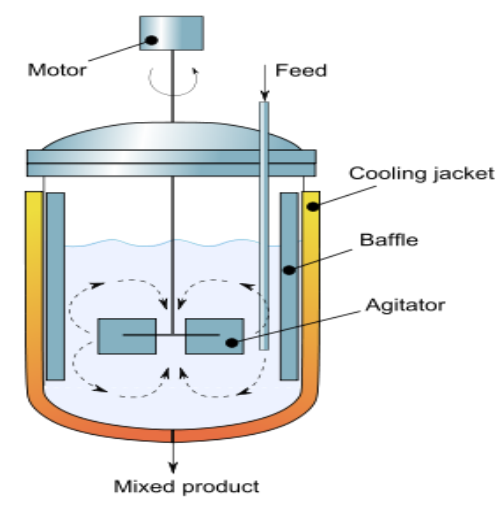

Figure 1 Cross section of CSTR

In the chemical industry, it is utilized for the ideal mixture of chemicals which are consistently added to the reactor and gives comparative arrangement of input chemical and output mixture. Desired rate of change of substrate into a product is acquired through the industrious decision of tank size, enzymatic movement and rate of addition of substrate.

For example, a minimal stream rate, an expansive reactor size, and high enzymatic movement will prompt maximal itemyields. minimal support cost andstraightforwardness of purification, basic development, capacity to convey persistent activity are fundamentally basic crosswise over different mechanical applications. CSTR is routinely used as a movement of specific activator, ampleness of such planned reactors is basically dependent upon the value of activator and segment shape of the activator[8],[9],[10].

The general process expenses and setup amounts of CSTR are often automatically minimum than those of identical batch operation since such process can be taken in production facilities that are 10 to 100 times smaller. Their mathematical models depend on Nonlinear Ordinary Differential Equations (ODEs) which are used for preliminary investigation of the open-loop, closed-loop and steady-state behavior of chemical activator. In this research work, the various methods for controlling the parameters for CSTR are surveyed.

\section{Related Works}

This Research work examining the propelled control of a CSTR thus has a huge effect on various applications. Various control approach has implemented for CSTR control, like fuzzyand adaptive control. Despite the fact, these control methods have some limitations such as poor performance, complex design or the requirement for the control to be implemented with a human in the loop. In this part, some of the previously existed methods of CSTR and PID controller have been presented.

A Neural based network was developed to address a Fault Tolerant Control (FTC) issues such as stuck faults and adequacy faults for MIMO. CSTR is chosen to tackle the fault control issues. The diffeomorphism hypothesis is utilized to change the original system into the input-output system to set up a quick error replay. The result presents FTC method is connected to the similar CSTR. Performances results show that effective results of FTC and also diminish the computational burden [1].

A novel method was developed for control of multivariable industrial processes. It is a challenging problem in the industry, designing uncertainty, and different disorder [6]. PID controller is designed forcontinuous stirred tank reactor operation with decoupler to meet the desired transient responsedeterminations. The outputs presents proposed method is anything 
but difficult to apply when the process parameters are transformed from the nominal values and it accomplishes great tracking control of the concentration and temperature set points and approves the execution of the designed controllers[54].

An Unscented Kalman Filter (UKF) was proposed to accomplish the successful execution by the parameter and case measure of CSTR. In which UKFs utilize Nonlinear UTs in the identification stage with a specific end goal to protect stochastic qualities of a nonlinear system [5]. The UKF method is tested on CSTR to assess the non-linear issues and the graphical results illustrate the proposed strategy accomplishes accurate outcomes for uncertainties [48].

A disturbance observer was developed to evaluate the disturbance and a consequent stable [45]. A powerful limitation outline issue is a critical task to defeat this issue sliding mode control is utilized. The simulation results show that proposed strategy accomplishes effective result by choosing th e suitable design parameters, the nonlinear disturbance observer can display a rapid rate of convergence and lessen the tracking error[18],[19],[20].

A RMPC was proposed for a research center of CSTR[44]. The Hebky filter was intended to eradicate impact of estimation noise. 4 limit instances of group-mark catch are measured to explore the limited execution guaranteed by composed RMPC. Performance results were simulated on datasets of a few step-responses to guarantee excellent control performance [27].

A nonlinear CSTR is developed incorporated with dual controllers such as STR and MRAC alongside traditional PID and straight MPC [21]. This model intended to handle the Complex nonlinear systems dynamics depend on the applicability to a limitation scope of tasks to fulfill the execution and the proposed strategy accomplishes efficient results in Peak overshoot and settling time[11].

A nonlinear maximum gain viewer to offer an entire condition was analyzed. Synthetic process shows an abnormal state of nonlinearities and interconnections between states [12]. The simulation results are assessed for MIMO processor and to guarantee great relevance. In that second version accomplishes steady gain which clarifies the minimum suitable outcomes related to the initial report [13].

Implemented the virtual feedback control for the CSTR framework by utilizing filters. The traditional techniques at times give the poor outcomes to decide the ideal value [36]. The highly trained algorithm of PSO is introduced for the feedback control of CSTR and achieves the minimum integral square error by utilizing the virtual feedback PID PSO [14], [15].

A simplified model was developed for CSTR as NARMAX approach which is intended depend on a huge number of input and output information. Performance output presents proposed technique acquires accurate result for CSTR. The U-model limited based on the NARMAX approach is superior to the classical PID control technique accordingly replay fastness and limited precision [16].

A hybrid model was developed for real-time applications for CSTR. It analyzed about the dual-instruction limit of a nonlinear synthetic processor [52]. Fuzzy logic with damper rule was utilized. The simulation result shows that theproposed control system [7], [33].

Proposed CKF to offer dynamic and maximum depth with evaluation of CSTR. The proposed CKF delivered the highest accuracy and less execution time when similar to EKF and SUKF and it proves that CKF is spectators of nonlinear high-dimensional system CSTR [47].

Proposed CSTR to develop reliable bioprocess segment. Trial was done for the period of 225 days, the proposed method shown very effectively in cleaning the wastewater. The simulation results show that by implementing this proposed method, the corruption of hydrocarbons upgraded technique [4].

A continuous stirred tank reactor was designed which can be controlled by three methods such as feedback, feedforward and cascade. Proportional Integral Derivative (PID) controller is utilized to analyse the response and system stability. The simulation results show that the feedforward control has efficient response time compared to the feedback control system, and delivers an impressive offset a vast overshoot [17].

The self-tuning limitation and algorithm were presented for CSTR system. This PSO 
technique was trained by straightforward and fast training methods [37]. The PID neural control algorithm gives the maximum tracking error and smooth yield for the non-linear dynamical CSTR framework [31].

A controller was designed to assess the effective controller for CSTR. The experimental results are carried on MATLAB SIMULINK to identify the best controller [48]. In which the comparison depends on the specific reaction achieves the superior execution than a traditional PI controller [32].

An Artificial Intelligence technology was developed for CSTR to consolidating nonlinear dynamics system. Two non-linear models and the graphical outputs showthat traditional method and the neural model are evaluated and compared with respect to input variations [42].

An algorithm was proposed for recognizing semi-continuous synthetic reactor error based on high gain observers. Fault Detection Identification and Isolation (FDII) is intended to distinguish the multiple faults and this methodology works graphical outputs presents the proposed actuators accomplish simple and efficient detection results, for both single fault and multi-fault and the actuator is evaluated by a high gain observer[40].

A minimised order viewer in a dynamic processor was designed. The principle issues deal with the non-stationary process for some situation which prompts to accidents and solved by designing nonlinear reduced order spectator [28]. In this method merging of the estimation error is considered with quantifiable temperature. The simulation results are evaluated and the results achieve efficient estimation error converges to zero faster [29], [30].

A new algorithm was proposed for flower pollination algorithm to tackle a nonlinear design benchmark to lessen the convergence rate. In real time applications to handle troublesome issues meta-heuristics algorithms are utilized which indicates the effectiveoutcome [47]. The graphical outputs illustratethe flower algorithm is more accurate than both Genetic Algorithm and Particle Swarm Optimization in case of searching strategy [41], [43].

The ideal actual membership function of a fuzzy process utilizing PSO [35] was suggested by the author. The integration of fuzzy logic control with PSO algorithm was developed to control the CSTR model. Based on the controller design it achieves the acceptable and the accurate effective results [40].

The discussion of optimization techniques used for continuous stirred tank reactor. The techniques are GWO, BSA, DE and BA .it is outputs are clear that Grey Wolf Optimizer outperforms well when compared to other techniques.

A non-linear feedback controller was designed to examine the concentration and temperature control for CSTR [38]. The concentration of the CSTR can be controlled by utilizing particle swarm optimization based PID controller. Based on the performance Integral Square Error (ISE) of the framework was diminished by utilizing the PSO based PID controller [47].

An intelligent systems was proposed for temperature control of a continuous stirred tank reactor. The experimental results are evaluated in terms of SSE and Integral IAE Criteria in which, fuzzy based designed approach achieves thegreater adaptability and exact conduct in charge activity in identification to the minimum objective based method [46].

Table 1 shows the comparison of various methods and its limitations. The researchers have done research on parameters adjustment in CSTR for tuning the weight parameters in CSTR but still they face certain limitations. Form this comparison the limitations are identified and the new method is developed to overcome these limitations [34], [35].

Table 1 Comparison of Several Methods for CSTR

\begin{tabular}{|c|l|l|l|}
\hline $\begin{array}{c}\text { S.N } \\
\text { o }\end{array}$ & Authors & \multicolumn{1}{|c|}{ Methods } & Disadvantages \\
\hline 1 & Nekoui & $\begin{array}{l}\text { Particle Swarm } \\
\text { Optimization }\end{array}$ & $\begin{array}{l}\text { Computational } \\
\text { Complexity and } \\
\text { require more } \\
\text { computation } \\
\text { time. }\end{array}$ \\
\hline 2 & $\begin{array}{l}\text { Malar and } \\
\text { Thyagarajan }\end{array}$ & $\begin{array}{l}\text { Artificial } \\
\text { Neural Network }\end{array}$ & $\begin{array}{l}\text { High settling } \\
\text { time and more } \\
\text { training time to } \\
\text { train the } \\
\text { networks }\end{array}$ \\
\hline 3 & $\begin{array}{l}\text { Luangpaiboo } \\
\mathrm{n}\end{array}$ & $\begin{array}{l}\text { Firefly and Ant } \\
\text { Colony } \\
\text { Optimisation } \\
\text { Algorithms }\end{array}$ & $\begin{array}{l}\text { More noise } \\
\text { distortion } \\
\text { and } \\
\text { occurrence of } \\
\text { an error }\end{array}$ \\
\hline 4 & Kumar et al & Genetic & More delay \\
\hline
\end{tabular}




\begin{tabular}{|c|c|c|c|}
\hline & & Algorithm & $\begin{array}{l}\text { time and slow } \\
\text { convergence } \\
\text { rate }\end{array}$ \\
\hline 5 & Yasoobi et al & $\begin{array}{l}\text { Improved } \\
\text { Particle Swarm } \\
\text { Optimization }\end{array}$ & $\begin{array}{l}\text { High inertia } \\
\text { weight and low } \\
\text { convergence } \\
\text { rate }\end{array}$ \\
\hline 6 & Banu et al & Fuzzy Control & $\begin{array}{l}\text { Inaccurate and } \\
\text { rigorous and } \\
\text { inefficient to } \\
\text { identify the } \\
\text { membership } \\
\text { function for } \\
\text { large datasets }\end{array}$ \\
\hline 7 & Lahoty et al & $\begin{array}{l}\text { Evolutionary } \\
\text { Algorithms }\end{array}$ & $\begin{array}{l}\text { High premature } \\
\text { convergence to } \\
\text { a local extreme } \\
\text { may result not } \\
\text { yield the global } \\
\text { extremum. }\end{array}$ \\
\hline 8 & Perng et al & $\begin{array}{l}\text { Stochastic } \\
\text { Inertia Weight } \\
\text { Particle Swarm } \\
\text { Optimization } \\
\text { (SIWPSO) } \\
\text { Algorithm And } \\
\text { Radial Basis } \\
\text { Function } \\
\text { Neural Network }\end{array}$ & $\begin{array}{l}\text { More } \\
\text { Computational } \\
\text { time and } \\
\text { inefficient } \\
\text { global } \\
\text { optimization } \\
\text { weight }\end{array}$ \\
\hline 9 & Chang et al & $\begin{array}{l}\text { Artifical Bee } \\
\text { Colony } \\
\text { Optimization }\end{array}$ & $\begin{array}{l}\text { The inaccuracy } \\
\text { of the optimal } \\
\text { value which } \\
\text { cannot meet } \\
\text { the } \\
\text { requirements } \\
\text { and maximum } \\
\text { cost Function }\end{array}$ \\
\hline 10 & $\begin{array}{c}\text { Jalili- } \\
\text { Kharaajoo }\end{array}$ & $\begin{array}{c}\text { Neuro-Fuzzy } \\
\text { Model }\end{array}$ & $\begin{array}{l}\text { Inefficient to } \\
\text { estimate the } \\
\text { error }\end{array}$ \\
\hline 11 & $\begin{array}{l}\text { Baranilingesa } \\
\mathrm{n} \text { and Deepa }\end{array}$ & $\begin{array}{c}\text { Grey Wolf } \\
\text { Optimization }\end{array}$ & $\begin{array}{c}\text { Dynamic } \\
\text { changes of } \\
\text { properties such } \\
\text { as temperature, } \\
\text { concentration } \\
\text { and pressure } \\
\text { and high static } \\
\text { error time }\end{array}$ \\
\hline
\end{tabular}

Figure 2 shows the comparison of $k_{p}$ (Proportional gain) control parameters for efficient fluid flow in the reactor. The parameter is compared with Z-N method, Particle Swarm Optimization, Radial basis function neural network and
SIWPSO (stochastic inertia weight particle swarm optimization) algorithm is similar for every comparison graphical representation, genetic Algorithm and Grey Wolf Optimization for CSTR based PID Controller. Mainly these methods are implemented to adjust the parameter of CSTRreactor [23], [24], [25], [26].

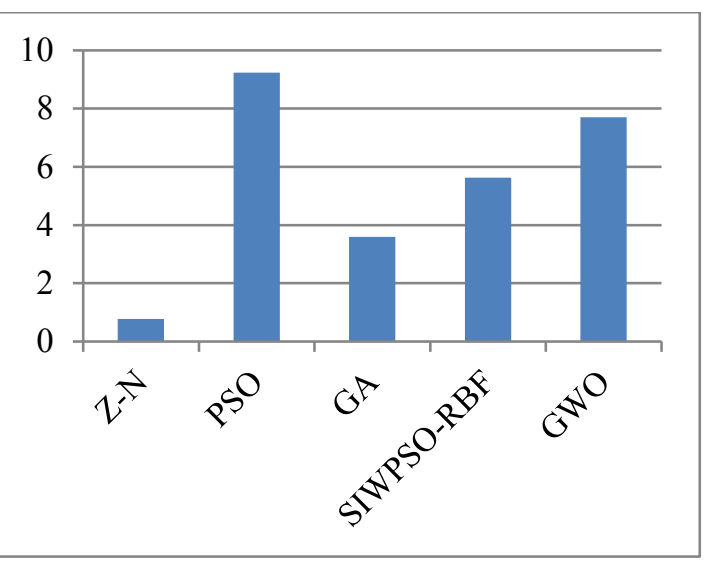

Figure $2 k_{p}$ Comparisons for Various Methods

Figure 3 shows the comparison of $k_{i}$ (Integral gain) control parameters for efficient fluid flow in the reactor. The parameter is compared with Z-N method, Particle Swarm Optimization, genetic Algorithm and Grey Wolf Optimization for CSTR based PID Controller.

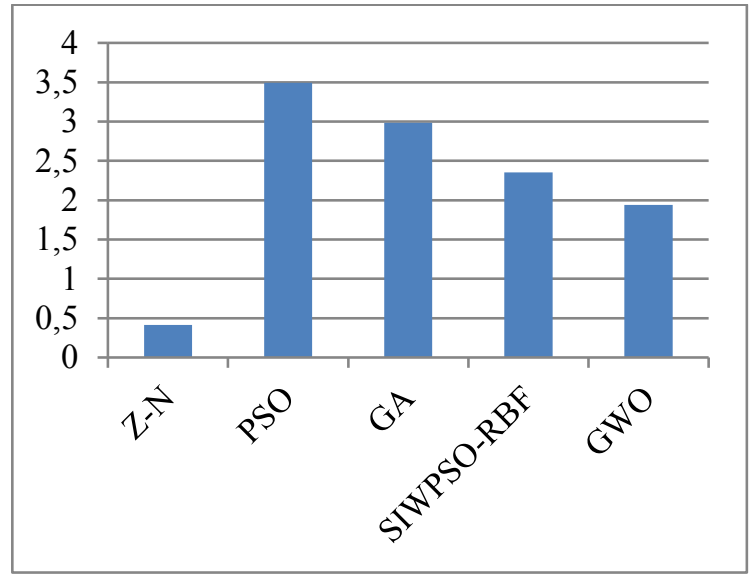

Figure $3 k_{i}$ Comparisons for Various Methods

Figure 4 shows the comparison of $k_{d}$ (Derivative gain) control parameters for efficient fluid flow in the reactor. The parameter is compared with Z-N method, Particle Swarm Optimization, genetic Algorithm and Grey Wolf Optimization for CSTR based PID Controller [22]. 


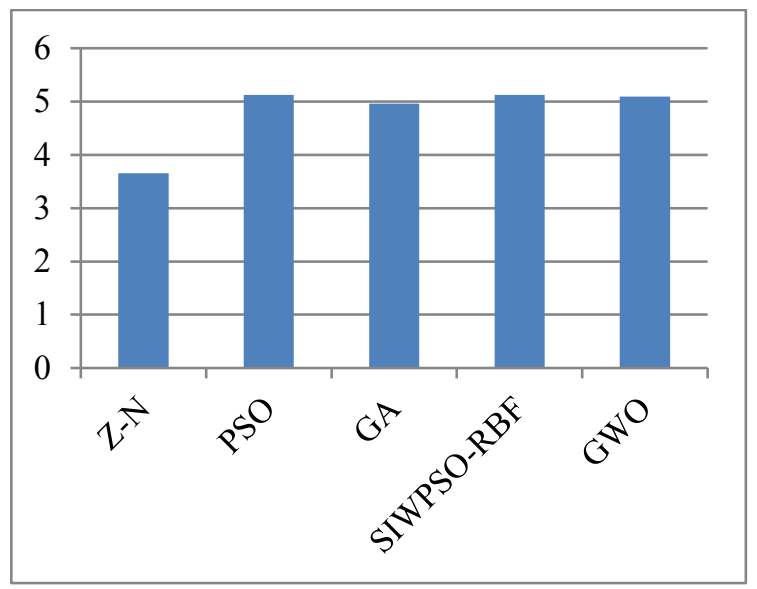

Figure $4 k_{i}$ Comparisons for Various Methods

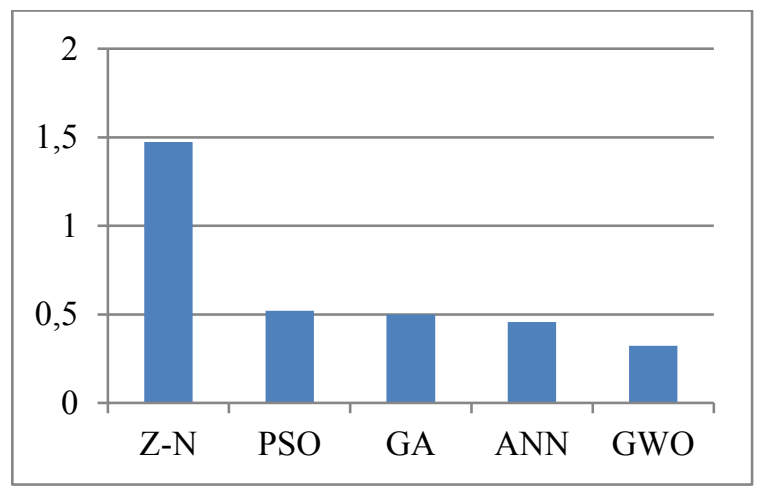

Figure 5 Comparison of ISE

Figure 5 shows the comparison of Integral Square Error parameters for efficient fluid flow in the reactor. The $k_{p}, k_{i}$ and $k_{d}$ parameteris used to adjust the fluid flow to minimize the ISE parameter. The evaluation is compared with Z-N method,ANN,PSO,GA and Grey Wolf Optimization for CSTR based PID Controller. These methods are employed to adjust the $k_{p}, k_{i}$ and $k_{d}$ parameter to decrease the ISE.

\section{Conclusion}

Nowadays it is necessary, that proper analysis of CSTR in chemical management in order to achieve the desired effective output. However, controlling the CSTR is a major concern for any engineer. This work depicted a wide survey on distinct schemes for CSTR, PID controller to adjust fluid flow by tuning certain parameters. Mainly this work concentrates in CSTR to minimize the Integral Square Error by various parameters and to offer better performance mutually. By comparing the simulation results of various methods it provides the satisfactory output response of reactor and performance criterions.

\section{References:}

[1]. Wang, Z., Liu, L., Li, T. and Zhang, H., 2017. Minimum-Learning-ParametersBased Adaptive Neural Fault Tolerant Control with Its Application to Continuous Stirred Tank Reactor. IEEE Transactions on Systems, Man, and Cybernetics: Systems.

[2]. Huaguang, Z., \&Cai, L. (2002). Nonlinear adaptive control using the Fourier integral and its application to CSTR systems. IEEE Transactions on Systems, Man, and Cybernetics, Part B (Cybernetics), 32(3), 367-372.

[3]. Mahmoud, M. S., \& Khalid, H. M. (2014). Model prediction-based approach to fault-tolerant control with applications. Ima journal of mathematical control and information, 31(2), 217-244.

[4]. Riveros, J. A. H., \&Piedrahita, G. R. (2016). Control for coupled process by collaborative set points movement over MIMO systems. IEEE Latin America Transactions, 14(12), 4663-4673.

[5]. Xie, L., Su, H., Lu, S., \&Xie, L. (2018). Linear Mismatched Model Based Offset-Free MPC for Nonlinear Constrained Systems with Both Stochastic and Deterministic Disturbances and Its Application to CSTR. IEEE Access, 6, 69172-69184.

[6]. Ling, Z. H., Richmond, K., \& Yamagishi, J. (2013). Articulatory control of HMM-based parametric speech synthesis using feature-space-switched multiple regression. IEEE Transactions on Audio, Speech, and Language Processing, 21(1), 207-219.

[7]. Wang, T., Qiu, J., Fu, S., \& Ji, W. (2017). Distributed Fuzzy \$ H_ \{infty\} \$ Filtering for Nonlinear Multirate Networked Double-Layer Industrial Processes. IEEE Transactions on Industrial Electronics, 64(6), 5203-5211.

[8]. Mosalanejad, M., \&Arefi, M. M. (2018). UKF-based soft sensor design for joint estimation of chemical processes with multi-sensor information fusion and infrequent measurements. IET Science, Measurement \& Technology, 12(6), 755763.

[9]. Pan, Z., Dong, F., Zhao, J., Wang, L., Wang, H., \& Feng, Y. (2018). Combined resonant controller and two-degree-offreedom PID controller for PMSLM current 
harmonics suppression. IEEE Transactions on Industrial Electronics, 65(9), 7558-7568.

[10].Angel, L., \& Viola, J. (2015). Design and statistical robustness analysis of FOPID, IOPID and SIMC PID controllers applied to a motor-generator system. IEEE Latin America Transactions, 13(12), 3724-3734.

[11].Merayo, N., Juárez, D., Aguado, J. C., De Miguel, I., Durán, R. J., Fernández, P., ... \& Abril, E. J. (2017). PID controller based on a self-adaptive neural network to ensure QoS bandwidth requirements in passive optical networks. Journal of Optical Communications and Networking, 9(5), 433-445.

[12].Marin, A. M. C. A., Hernand, J. A. H. R. J., \& Jimenez, J. A. J. B. J. (2018). Tuning Multivariable Optimal PID Controller for a Continuous Stirred Tank Reactor Using an Evolutionary Algorithm. IEEE Latin America Transactions, 16(2), 422-427.

[13].Camarillo-Gómez, K. A., Pérez-Soto, G. I., \& Rodríguez-Reséndiz, J. (2018). Comparison of PD, PID and Sliding-Mode Position Controllers for V-Tail Quadcopter Stability. IEEE Access, 6, 38086-38096.

[14].Torres, W. L., Araujo, I. B. Q., Menezes Filho, J. B., \& Junior, A. G. C. (2017). Mathematical Modeling and PID Controller Parameter Tuning in a Didactic Thermal Plant. IEEE Latin America Transactions, 15(7), 1250-1256.

[15].Han, Z., Li, Y., \& Liang, J. (2018). Numerical Improvement for the Mechanical Performance of Bikes Based on an Intelligent PSO-ABC Algorithm and WSN Technology. IEEE Access, 6, 32890-32898.

[16].Zhang, H., Xu, G. L., Yin, W., Wang, H. B., $\&$ Ge, P. (2018). Numerical Investigation on the Transmission Loss of Skin Panels Based on the Intelligent PSO-CGA Algorithm. IEEE Access, 6, 26121-26130.

[17].Moghaddam, S. H. A., Mokhtarzade, M., \&Moghaddam, S. A. A. (2018). Optimization of RFM's Structure Based on PSO Algorithm and Figure Condition Analysis. IEEE Geoscience and Remote Sensing Letters, 15(8), 1179-1183.

[18].Prasad, S., \& Kumar, D. V. (2017). Optimal allocation of measurement devices for distribution state estimation using multiobjective hybrid PSO-krill herd algorithm. IEEE Transactions on Instrumentation and Measurement, 66(8), 2022-2035.
[19].Emary, E., Zawbaa, H. M., \&Grosan, C. (2018). Experienced gray wolf optimization through reinforcement learning and neural networks. IEEE transactions on neural networks and learning systems, 29(3), 681-694.

[20].Mohanty, S., Subudhi, B., \& Ray, P. K. (2016). A new MPPT design using grey wolf optimization technique for photovoltaic system under partial shading conditions. IEEE Transactions on Sustainable Energy, 7(1), 181-188.

[21].Jiang, T., \& Zhang, C. (2018). Application of Grey Wolf Optimization for solving combinatorial problems: Job shop and flexible job shop scheduling cases. IEEE Access, 6, 26231-26240.

[22].Rashidi, K., Mirjalili, S. M., Taleb, H., \&Fathi, D. (2018). Optimal Design of Large Mode Area Photonic Crystal Fibers Using a Multiobjective Gray Wolf Optimization Technique. Journal of Lightwave Technology, 36(23), 56265632.

[23].Daniel, E. (2018). Optimum WaveletBased Homomorphic Medical Image Fusion Using Hybrid Genetic-Grey Wolf Optimization Algorithm. IEEE Sensors Journal, 18(16), 6804-6811.

[24].Mohanty, S., Subudhi, B., \& Ray, P. K. (2017). A grey wolf-assisted perturb \& observe MPPT algorithm for a PV system. IEEE Transactions on Energy Conversion, 32(1), 340-347.

[25].Castro, P. A. D., \& Von Zuben, F. J. (2011). Learning ensembles of neural networks by means of a Bayesian artificial immune system. IEEE Transactions on Neural Networks, 22(2), 304-316.

[26].Lv, J. C., Yi, Z., \& Li, Y. (2015). Nondivergence of stochastic discrete time algorithms for PCA neural networks. IEEE transactions on neural networks and learning systems, 26(2), 394-399.

[27].Arami, A., Martins, N. V., \&Aminian, K. (2015). Locally Linear Neuro-Fuzzy Estimate of the Prosthetic Knee Angle and Its Validation in a Robotic Simulator. IEEE Sensors Journal, 15(11), 6271-6278.

[28].Miranian, A., \&Abdollahzade, M. (2013). Developing a local least-squares support vector machines-based neuro-fuzzy model for nonlinear and chaotic time series prediction. IEEE Transactions on Neural Networks and Learning Systems, 24(2), 207-218. 
[29].Liu, Y., Zhang, W., \& Zhang, Y. (2015). Dynamic neuro-fuzzy-based human intelligence modeling and control in GTAW. IEEE Transactions on Automation Science and Engineering, 12(1), 324-335.

[30].Li, W., Hu, X., Gravina, R., \&Fortino, G. (2017). A neuro-fuzzy fatigue-tracking and classification system for wheelchair users. IEEE Access, 5, 19420-19431.

[31]. Nekoui, M.A., Khameneh, M.A. and Kazemi, M.H., 2010, September. Optimal design of PID controller for a CSTR system using particle swarm optimization. In Power Electronics and Motion Control Conference (EPE/PEMC), 2010 14th International (pp. T7-63). IEEE.

[32]. Luangpaiboon, P., 2011. Continuous stirred tank reactor optimisation via simulated annealing, firefly and ant colony optimisation elements on the steepest ascent. International Journal of Machine Learning and Computing, 1(1), p.58.

[33]. Jalili-Kharaajoo, M., 2003, August. Predictive control of a continuous stirred tank reactor based on neuro-fuzzy model of the process. In SICE 2003 Annual Conference (Vol. 3, pp. 3277-3282). IEEE.

[34]. Baranilingesan, I. and Deepa, S.N., 2017. A Novel Grey Wolf Optimization Approach Based Continuous Stirred Tank Reactor.

[35]. Vaneshani, S. and Jazayeri-Rad, H., 2011. Optimized fuzzy control by particle swarm optimization technique for control of CSTR. World Academy of Science, Engineering and Technology, 59, pp.686691.

[36]. Geetha, M., Balajee, K.A. and Jerome, J., 2012, March. Optimal tuning of virtual feedback PID controller for a continuous stirred tank reactor (CSTR) using particle swarm optimization (PSO) algorithm. In Advances in Engineering, Science and Management (ICAESM), 2012 International Conference on (pp. 94-99). IEEE.

[37]. Dagher, K.A. and Al-Araji, A.S., 2013. Design of an Adaptive PID Neural Controller for Continuous Stirred Tank Reactor based on Particle Swarm Optimization. Al-Khwarizmi Engineering Journal, 9(4).

[38]. Agalya, A. and Nagaraj, B., 2013. Certain Investigation on Concentration Control of CSTR-A. Comparative
Approach. Int. J. Adv. Soft Comput. Appl, 5(2), pp.2024-2031

[39]. Niu, M., \& Xu, Z. (2014). Efficiency ranking-based evolutionary algorithm for power system planning and operation. IEEE Transactions on Power Systems, 29(3), 1437-1438.

[40].Yu, Y., Qian, C., \& Zhou, Z. H. (2015). Switch analysis for running time analysis of evolutionary algorithms. IEEE Transactions on Evolutionary Computation, 19(6), 777-792.

[41].Zhu, C., Xu, L., \& Goodman, E. D. (2016). Generalization of Paretooptimality for many-objective evolutionary optimization. IEEE Transactions on Evolutionary Computation, 20(2), 299-315.

[42].Bezerra, L. C., López-Ibánez, M., \&Stützle, T. (2016). Automatic component-wise design of multiobjective evolutionary algorithms. IEEE Transactions on Evolutionary Computation, 20(3), 403-417.

[43].Yuan, B., Li, B., Chen, H., \& Yao, X. (2015). A new evolutionary algorithm with structure mutation for the maximum balanced biclique problem. IEEE transactions on cybernetics, 45(5), 10541067.

[44].Muramatsu, J., Kojima, T., Tanaka, H., Hattori, Y., Okada, H., Keino, H., ...\& Fujisaki, K. (2015). Non-linear numerical expression of surge voltage for electromagnetic clutch. IEEE Transactions on Magnetics, 51(3), 1-4.

[45].Gaba, S., Cai, F., Zhou, J., \& Lu, W. D. (2014). Ultralow sub-1-nA operating current resistive memory with intrinsic non-linear characteristics. IEEE Electron Device Letters, 35(12), 1239-1241.

[46].Araneo, R., Bini, F., Pea, M., Notargiacomo, A., Rinaldi, A., \&Celozzi, S. (2016). Impact of non-linear piezoelectricity on the piezotronic effect of $\mathrm{ZnO}$ nanowires. IEEE Transactions on Nanotechnology, 15(3), 512-520.

[47].Yang, M., Sima, W., Yang, Q., Li, J., Zou, M., \&Duan, Q. (2017). Non-linear characteristic quantity extraction of ferroresonance overvoltage time series. IET Generation, Transmission \& Distribution, 11(6), 1427-1433.

[48].Yao, W. S., \& Tsai, M. C. (2005). Analysis and estimation of tracking errors of plug-in type repetitive control systems. 
IEEE Transactions on Automatic Control, 50(8), 1190-1195.

[49].Zhu, H. Y., Wu, H. N., \& Wang, J. W. (2018). Fuzzy control with guaranteed cost for nonlinear coupled parabolic PDE-ODE systems via PDE static output feedback and ODE state feedback. IEEE Transactions on Fuzzy Systems, 26(4), 1844-1853.

[50].Zhu, H. Y., Wu, H. N., \& Wang, J. W. (2017). \$ H_linfty \$ Disturbance Attenuation for Nonlinear Coupled Parabolic PDE-ODE Systems via FuzzyModel-Based Control Approach. IEEE Transactions on Systems, Man, and Cybernetics: Systems, 47(8), 1814-1825.

[51].Al-Omari, A., Arnold, J., Taha, T., \&Schüttler, H. B. (2013). Solving large nonlinear systems of first-order ordinary differential equations with hierarchical structure using multi-GPGPUs and an adaptive RungeKutta ODE solver. IEEE Access, 1, 770-777.

[52].Miletić, M., Stürzer, D., Arnold, A., \&Kugi, A. (2016). Stability of an EulerBernoulli beam with a nonlinear dynamic feedback system. IEEE Transactions on Automatic Control, 61(10), 2782-2795.

[53].Jafari, R., Yu, W., \& Li, X. (2016). Fuzzy differential equations for nonlinear system modeling with bernstein neural networks. Ieee Access, 4, 9428-9436.

[54].Feng, S., \& Wu, H. N. (2017). Hybrid robust boundary and fuzzy control for disturbance attenuation of nonlinear coupled ODE-beam systems with application to a flexible spacecraft. IEEE Transactions on Fuzzy Systems, 25(5), 1293-1305.

\section{Creative Commons Attribution License 4.0 (Attribution 4.0 International, CC BY 4.0)}

This article is published under the terms of the Creative Commons Attribution License 4.0

https://creativecommons.org/licenses/by/4.0/deed.en_US 